\title{
¿QUÉ HACEMOS CON EL MIEDO? DIÁLOGOS ENTRE ESTUDIANTES Y MUJERES EN EL BARRIO. EXPERIENCIAS EN SAN JUAN DE PAVAS, SAN JOSÉ
}

\section{WHAT DO WE DO WITH FEAR? DIALOGUES BETWEEN STUDENTS AND WOMEN IN THE NEIGHBORHOOD. EXPERIENCES IN SAN JUAN, PAVAS, SAN JOSÉ}

\author{
Laura Paniagua Arguedas* \\ Heiner Mora Valverde ${ }^{* *}$
}

Fecha de recepción: 16 de diciembre de 2017 - Fecha de aceptación: 8 de junio 2018

\section{Resumen}

El artículo presenta reflexiones provenientes de la investigación acción vinculada al trabajo con comunidades en zonas que enfrentan empobrecimiento. En éste, se elaboran consideraciones a partir de la experiencia pedagógica con estudiantes de Trabajo Comunal Universitario (TCU) en intercambio con la comunidad de Finca San Juan en Pavas, San José. Por medio de talleres, esculturas humanas y el diálogo entre las mujeres de la comunidad y las estudiantes, se elabora un análisis sobre el miedo cotidiano para tratar de entender su origen, manifestaciones, experiencias vinculadas y qué se puede hacer con él. El artículo aporta un análisis de los aprendizajes de este grupo e incorpora discusiones surgidas en el marco de un foro universitario, que permite presentar la discusión sobre el papel de la acción social universitaria en las comunidades. El análisis concluye que el miedo debe ser entendido en las relaciones sociales pues tiene un papel importante en las subjetividades y marca la formación de lazos sociales de las personas en el barrio. Además, de que el fortalecimiento de la relación entre las comunidades y la universidad propicia las mejores condiciones de trabajo para vecinos y estudiantes.

Palabras clave: Lazo social; Comunidad; Investigación participativa; Aprendizaje activo; Acción comunitaria; Miedo.

\section{Abstract}

The article reflects on the action research linked to the work with communities that face impoverishment. Some arguments are presented based on the teaching experience of students from the university communal work in exchange with the Finca San Juan's community in Pavas, San José. Through workshops, human sculptures and the dialogue between women and students from this community, fear is analyzed in order to understand its origins, manifestations, related experiences, and possible solutions. This article evaluates this group experiences and concludes that fear must be studied within social relationships since it has an important role in the neighborhood's social ties and festivities.

Key Words: Social Ties; Community; Participatory Research; Active Learning; Community Action; Fear.

* Universidad de Costa Rica, Docente e Investigadora, Escuela de Sociología, el Instituto de Investigaciones Sociales y la Escuela de Arquitectura, Doctoranda en Urbanismo por la Universidad Nacional Autónoma de México, laura.paniagua@ ucr.ac.cr

** Universidad de Costa Rica, Egresado de la Licenciatura en Arquitectura y Estudiante activo del Bachillerato y Licenciatura en Filosofía, heiner_mv@hotmail.com 


\section{Introducción}

El interés de este artículo es compartir los diálogos acerca del miedo ocurridos en el año 2014 entre un grupo de estudiantes de Trabajo Comunal Universitario y las mujeres de San Juan en Pavas. El intercambio fue motivado por el temor de las estudiantes a estar en la comunidad después de un episodio de violencia cuando, una tarde, las jóvenes se encontraban en el salón comunal trabajando y un hombre le disparó a otro en un autobús, cerca del sitio. Fue este evento el que propició que se compartieran los temores mutuos y se planteara la discusión sobre la realidad que enfrenta el país y Centroamérica.

El Trabajo Comunal Universitario es un ámbito de la acción social que realiza todo estudiante en la Universidad de Costa Rica para concluir su formación profesional, con 300 horas de labores en proyectos con las comunidades. En este artículo se analiza la experiencia que ha sido parte del proyecto TC-568 Promoción de una cultura de respeto y solidaridad en el contexto de las migraciones en Costa Rica, perteneciente a la Escuela de Arquitectura, entre los años 2011-2017.

En el transcurso de varias sesiones con las estudiantes se estableció la pregunta ¿qué hacemos con el miedo?, misma que tiene diferentes temporalidades: hoy, en el día a día, en la calle, en el barrio, en la universidad, en nuestras vidas, sobre el presente y el futuro, ante lo incierto y lo conocido. Sin contar con una respuesta previa, se les planteó la posibilidad de trabajar en conjunto algunos análisis y aprendizajes con las personas involucradas en el proyecto de trabajo comunal. De dicha experiencia proviene esta reflexión.

Debemos agradecer a Georgina, María Fernanda, Diego, María del Carmen, Auxiliadora, Andrea, Alejandro, Rosario, María y sus nietos, quienes nos permitieron construir las reflexiones para dialogar en esta ocasión. Además, agradecemos la recomendación del profesor Randall Viales que nos sugirió utilizar las esculturas humanas como una de las técnicas para el abordaje de la situación.

El artículo se divide en tres secciones. La primera presenta un análisis sobre el concepto de miedo, como punto de partida para establecer sus dimensiones como sentimiento, construcción social y mecanismo de control. La segunda parte consta de las reflexiones de las mujeres y estudiantes sobre los miedos. Finalmente, en la última sección, se amplía el diálogo y se discute sobre el miedo como experiencia cotidiana, se comparte el punto de vista psicoanalítico, y la experiencia de una dirigente comunal; este conjunto de reflexiones facilita una visión integral del fenómeno del miedo y de la violencia social, lo cual enriquece la discusión.

\section{Puntos de partida}

Se emprendió esta tarea bajo la recomendación del maestro Paulo Freire (2010): "No permita que el miedo a la dificultad lo paralice" (p. 59), teniendo en cuenta que debe prestársele amplia atención a aquello que despierta nuestros más profundos sentimientos de desprotección. Como lo plantea Freire (2010):

Frente al miedo, sea lo que fuere, es preciso que primeramente nos aseguremos con objetividad de la existencia de las razones que nos lo provocan. En una segunda instancia, si éstas existen realmente, que las comparemos con las posibilidades de las que disponemos para enfrentarlas con probabilidades de éxito. Y, por último, que pensemos qué podemos hacer para, si éste es el caso, aplazar el enfrentamiento del obstáculo y volvernos más capaces de hacerlo mañana (p. 60).

Dando un lugar importante a las subjetividades que se vinculan con el trabajo de campo se busca abrir una discusión franca respecto al "miedo". Una pregunta hecha por las estudiantes nos cuestiona como docentes: "profe, ¿cómo hace usted para no tener miedo?” Lo que cabe entonces es reconocer que nuestros miedos son otros, incluyendo el de la posibilidad de que a un o una estudiante le ocurra algo en el trabajo en comunidad. Como lo señala Freire (2010): 
En un ejercicio de humildad, el educador reconoce su miedo para sobreponerse al mismo: Hablando de su miedo, de su inseguridad, el educador por un lado va haciendo una especie de catarsis indispensable para el control del miedo, y por el otro se va ganando la confianza de los educandos (p. 89).

Las reflexiones sobre el miedo no deben hacernos perder de vista que este tema es parte de un contexto social más amplio, que el miedo contemporáneo tiene una historia, y que constituye una oportunidad de aprendizajes para la gestión de riesgo y el trabajo con comunidades. Cabe indicar, que, el posicionamiento político del facilitador o facilitadora precisa una reflexión sobre sus referentes con respecto a la transformación social y el bienestar de las poblaciones con menores recursos. El miedo no se encuentra aislado de una recuperación de la dimensión ética en el trabajo en comunidad, temática que se elaborará al finalizar el artículo.

Eran las 2:40 de la tarde de un miércoles común y corriente. Hacía un rato, una pareja de estudiantes de Trabajo Comunal había llegado, como de costumbre, al salón comunal para comenzar con la sesión de alfabetización con las mujeres. Ese día se ausentaron varias compañeras, pero ya se había iniciado con el trabajo del día. En unos minutos ocurriría un evento que les pondría en alerta. A pocos metros del salón comunal, en el autobús, un hombre disparó a otro hiriéndole. Todo fue muy rápido, ellas escucharon los disparos. Existen varias versiones de lo ocurrido: "fue un intento de asalto", "fue una venganza". Lo importante es que este hecho de violencia desencadenó una serie de temores, principalmente entre el grupo de estudiantes.

Desde sus comienzos, en el año 2009, en la experiencia del proyecto de TC-568, el miedo o las referencias al miedo han sido un tema recurrente, cuando se daba a conocer las comunidades con las cuales trabajamos al grupo de estudiantes que se incorporaba cada ciclo. Barrio Nuevo en Curridabat, La Carpio en La Uruca, San Juan en Pavas, Linda Vista de Goicoechea, Brisas II en Tres Ríos, El Relleno en Pavas y La Deportiva en Alajuelita son algunas de esas comunidades con las que hemos laborado en estos años. En no pocos casos, las y los estudiantes manifestaron su inquietud o resistencia a ir a estos barrios y, en algunas oportunidades (al menos tres), han solicitado directamente retirarse del TCU, atribuyendo su decisión a la "inseguridad" en las comunidades en las que se trabaja.

En una ocasión, conocimos del caso de un estudiante que invirtió en una segunda línea telefónica, con un teléfono de "menor valor", que era el que llevaba al trabajo de campo, para no "exponer" sus bienes en la comunidad. Otros, pedían a sus padres o familiares que los llevaran y sacaran directamente de la comunidad. Esos discursos del miedo, del caos o del pánico moral, como los identifica María del Carmen Araya (2010) forman parte de todo el engranaje social y, aunque no correspondan enteramente con la realidad de las comunidades, terminan por incorporarse en la cotidianidad.

Al respecto la autora comenta: "Estas visiones se difunden aceleradamente por los medios de comunicación y se transforman en evaluaciones del Gobierno Local: San José "abandonado", "degenerado", "deshabitado", "anárquico" e ingobernable; así como en quimeras colectivas que se asientan en el sentido común" (p. 345). De ahí que resulte tan simple hacer asociaciones entre estas comunidades y atributos como violencia, miedo o inseguridad. A esto se suma el aspecto, en muchos casos, deteriorado de los edificios y viviendas, la carencia de espacios públicos adecuados o la poca inversión en obra pública. Para Barrera (2009), la sociedad colabora a intensificar el miedo, magnificando la información alarmista que se difunde en medios.

El papel de los medios es central en la percepción que tenemos del país y de las comunidades. Focás y Kessler (2014) lo evidencian al mostrar que ese percibir la comunidad, es también percibir o visualizar mi posición en ella. Al respecto comentan, "Para la mayoría, la estigmatización mediática se traducía en un sentimiento de vergüenza y los habitantes del barrio tendían a autopercibirse desde las categorías que los medios y otras instituciones habían generado sobre ellos" (2014, pp. 141-142). Con este panorama, es un reto el que nos señala Freire (2010): 
El miedo es un derecho más al que corresponde el deber de educar, de asumirlo para superarlo. Asumir el miedo es no huir de él, es analizar su razón de ser, es medir la relación entre lo que lo causa y nuestra capacidad de respuesta. Asumir el miedo es no esconderlo, solamente así podremos vencerlo (p. 88).

Este escrito persigue justamente esto. Evidenciar una de las emociones que más puede afectar la forma en la cual trabajamos con las comunidades. Las percepciones e imaginarios sobre la población de los barrios y sobre su entorno, marcan la forma en la cual nos acercamos y se encuentran presentes en la forma en la cual trabajamos. Así lo señalan Valdez, Huerta y Pérez (2014) cuando definen el miedo como "una perturbación angustiosa del ánimo por la percepción del individuo sobre un riesgo o daño real o imaginario, mismo que tiene un efecto real en su conducta y sus sentimientos" (p. 134). Los autores comentan, además, que es un esquema de supervivencia inscrito en nuestra psique, una emoción que nos impulsa a resguardarnos del peligro, y de la que no podemos tener control inmediato. Zygmunt Bauman (2007) ubica tres orígenes del miedo contra los que lucha el ser humano: "contra las fuerzas superiores de la naturaleza, contra los puntos débiles innatos de nuestros cuerpos y contra los peligros que emanan de la agresión de otras personas" (p. 167).

En tanto mecanismo de defensa, el miedo tiene efectos sobre la conducta y el ánimo, inhibiendo al sujeto y obstruyendo la capacidad de acción o, de forma opuesta, generando respuestas apresuradas e irracionales. De ahí que tenga consecuencias tanto a nivel individual como a nivel público. Además, los autores afirman que "el miedo es un instrumento ejemplar de represión" (Valdez et al., 2014, p. 134) en manos de los agentes de dominación económica, cultural o política. El miedo se construye y se ejerce para tener control sobre las personas, aprovechándose de que la política basa su accionar en la movilización de las emociones humanas.

Los autores colocan al miedo como el principio de acción política por antonomasia en las democracias contemporáneas, lo que no es de extrañar porque ya en el siglo XVII Thomas Hobbes lo propone como elemento central de la organización política (Kortanje, 2009, p. 3). Sean hechos de violencia aislados (un robo, por ejemplo) o, por otro lado, estrategias del poder político para imponer un orden específico de las cosas y las personas, se aspira a conseguir un objetivo puntual a costa del temor que se infunde en el otro. Múltiples autores hablan del miedo como una "tecnología", como "síntoma de la vida moderna", como forma para describir "la era en que vivimos" y como "cultura del miedo" (Furedi, 1997; Dunant y Porter, 1996 citados por Ahmed, 2017, p. 119). Para Ahmed, existen economías globales del miedo que se da en una política afectiva del miedo, en esa línea de pensamiento las emociones circulan a través de los objetos, "las emociones de odio y miedo toman forma a partir de la "zona de contacto" en la que otros nos impresionan y dejan sus impresiones" (Ahmed, 2017, p. 292).

No es para nada casual que el miedo surja ante barrios populares. Si bien existen manifestaciones o momentos de violencia en estas comunidades, no es posible generalizar que todas las personas que allí habitan sean violentas o peligrosas. La violencia puede aparecer en cualquier lugar. Sin embargo, una de las características de la actual fase del capitalismo mundial tiende a la criminalización de la pobreza, como lo llama Loïc Wacquant (2006), de manera que se logra:

transformar un problema político, enraizado en la desigualdad económica e inseguridad social, en un problema de criminalidad. Y para tratarlo utiliza el sistema policial, carcelario, judicial, a fin de no tener que tratar la realidad política y económica que está detrás de él. Desgraciadamente [...] esta política, inventada en Estados Unidos en las décadas de 1980 y 1990, ha sido exportada rápidamente a todo el mundo. (p.61)

La criminalización y estigmatización persiguen objetivos políticos y tienen consecuencias para la subjetividad de quienes las enfrentan:

cuando un área ha sido muy estigmatizada, las personas no se identifican con ella, no se sienten ligadas con otros, quieren evitar el estigma y se lo pasan unos a otros. Este fenómeno crea distancia social entre los residentes, crea desconfianza social y socava la posibilidad de la solidaridad, así como la posibilidad de acción colectiva e incluso la capacidad de protestar políticamente. (Wacquant, 2006, p.63) 
Sin embargo, las tendencias de securitización modernas nos llevan a desconfiar de todos y pensar que los lugares seguros son "los más vigilados". Con ello se legitima la represión y el control más que el derecho a un ambiente sano y a una ciudad inclusiva. Es a lo que Bauman se refiere cuando dice que somos una sociedad que se alimenta del miedo, siempre preparados, para consumir soluciones contra el miedo:

La economía de consumo depende de la producción de consumidores y los consumidores que hay que producir para el consumo de productos "contra el miedo" tienen que estar atemorizados y asustados, al tiempo que esperanzados de que los peligros que tanto temen puedan ser forzados a retirarse y de que ellos mismos sean capaces de obligarlos a tal cosa (con ayuda pagada de su bolsillo, claro está). (Bauman, 2007, p. 17).

Las formas de construcción del miedo y la otredad presentan formas sociales más complejas que requieren atención. Tal como lo señala Elias (2016):

La estigmatización, como aspecto de una relación entre establecidos y marginados, suele asociarse con un tipo específico de fantasía colectiva desarrollado por el grupo establecido. Al mismo tiempo que refleja la aversión (el prejuicio) que sus miembros sienten hacia los integrantes del grupo marginado, la justifica. (p. 50)

Pero ¿podemos constatar algún cambio en las situaciones de violencia en las comunidades en relación con los años anteriores? Una de las evidencias más claras es el narcotráfico y su introducción en la vida cotidiana de los barrios empobrecidos. Esta incursión se verifica en la violenta relación entre personas, grupos e inclusive entre las personas y el espacio que habitan. Situación que se agrava si se habla de barrios en los cuales la inversión estatal no ha llegado o llegó de forma superficial y el deterioro social, estructural y simbólico es más palpable. Sus situaciones de violencia se relacionan directamente con el sistema económico y las dinámicas de segregación y exclusión social que enfrenta su gente.

Todo esto ayuda a ampliar la brecha entre quienes más tienen y quienes no poseen recursos, pues la tendencia es a alejarse lo más posible de estos espacios, sino espacialmente por lo menos simbólicamente, anteponiendo al discurso del miedo y la violencia el de la distinción, el prestigio o la abundancia (Cfr. Araya, 2010). A pesar de eso, y como lo han demostrado diversas investigaciones (Caldeira, 2007 por ejemplo), muchos de los barrios donde habita la mayor riqueza se sirven de los servicios de los barrios empobrecidos. Su interacción se practica, aunque se invisibilice. En este caso, como en el de las estudiantes, hay una relación directa entre poseer bienes materiales y sentir miedo: "quien posee, teme; temiendo más, el que más tiene" (Valdez et al., 2014, p. 136).

Así representado, el miedo adquiere la apariencia de lo otro, diferente, vagamente definido porque "nos genera desconfianza, rechazo y oposición hacia unos (los que amenazan) y simpatía, afecto y solidaridad hacia los otros (los que protegen)" (Huerta et al., 2014, p. 141). Pero ¿qué pasa cuando esos límites no son claros, cuando no es posible diferenciar la fuente del miedo? La consecuencia inmediata es una desconfianza generalizada que dificulta aún más la creación del lazo social.

En este movimiento de ubicación de lo otro está definiéndose también la propia subjetividad. Es la autoafirmación de los sujetos individuales o colectivos por oposición a lo que no son. Así, no se debe permitir que situaciones de conflicto y miedo no resueltas estén en la base de nuestra subjetividad, sino que, como afirma Das (2003, traducido del original), la subjetividad se localiza en el esfuerzo de hacer cada día "vivible", o por así decirlo en la recuperación de nuestros espacios vitales, en el hacer del mundo, del barrio, nuestro mundo, nuestro barrio.

Como se ve, no se trata de si el miedo es una emoción pasajera o una situación aislada. Barrera (2009) comenta, "las emociones están directamente relacionadas con los significados, y de hecho no se produce ningún cambio emocional sin que se produzca un cambio cognitivo" (Barrera, 2009, p. 10). La forma instintiva en que reaccionamos tiene un peso cognitivo en la forma en como entendemos el mundo y nos desenvolvemos en él. De ahí la importancia de diálogo en comunidad sobre nuestro miedo, de generar una respuesta adecuada. Esto es, importante, no solo para las personas en la comunidad, sino 
también para quienes nos involucramos a trabajar con ellas, estudiantes o profesionales, pues somos agentes externos a la comunidad, y nuestra presencia siempre genera una reacción, es inevitable llamar la atención. Pero esto no debe provocar temor, sino que recalca la necesidad de fortalecer los lazos que se crean con los vecinos y vecinas. Se destaca también lo necesaria que es la discusión en el ambiente universitario y en la preparación a profesores y profesoras sobre cómo llevar estos procesos; se requiere el establecimiento de protocolos básicos, acordados entre la comunidad universitaria de las facultades para abordar, desde la gestión del riesgo, la aproximación a las comunidades y las diversas situaciones que pueden tener lugar en el trabajo de campo.

De cualquier modo, y como tema inicial, si se llega con prejuicios a las comunidades (como los difundidos en los medios de comunicación), cualquier indicio de violencia no hará más que reforzar esa imagen y acrecentará el miedo y la inseguridad que se siente, aunque sea un hecho aislado.

\section{Hablar y reflexionar: un primer paso para la liberación}

Al conversar con las estudiantes sobre la pregunta ¿desde dónde podemos pensar el miedo?, sobre sus sentimientos de inseguridad y temores por la idea de volver al trabajo, fue posible reflexionar sobre sus sensaciones y la de las personas con las cuales trabajan en la comunidad. Fue grato encontrar en ellas una respuesta distinta de la común en estudiantes de años anteriores que fue retirarse. Ellas desearon continuar, pero su sentimiento hacia la comunidad era contradictorio. Una de las estudiantes sintetizó lo vivido en palabras muy concretas "le perdimos confianza al lugar".

$\mathrm{Al}$ acompañar a las mujeres en un proceso de alfabetización se establecen lazos. Ellas pudieron testificar el esfuerzo e ilusión de las mujeres cuando comenzaron a alcanzar sus avances y con autonomía emprendieron el reto de las letras. Las estudiantes también conocieron el dolor y el miedo que viven estas mujeres en su entorno. Las historias que las mujeres les cuentan son vistas como momentos de terror. Doña Chayito lo expresó así: "ustedes se van, nosotras tenemos que quedarnos".

Una pareja de estudiantes decidió continuar al sentirse comprometida con el esfuerzo de las mujeres, mientras que las estudiantes que presentaron los mayores temores, decidieron cerrar su proceso con ese grupo, pues su percepción sobre la comunidad y su gente interfiere y se refleja en sus acciones. Otros elementos que aunaron a la sensación de inseguridad y vulnerabilidad para las estudiantes fueron la reducción en el apoyo por parte de la Asociación de Desarrollo Comunal de la localidad para este proyecto y las dificultades que impone la informalidad en el compromiso para atender los acuerdos iniciales para desarrollar el trabajo, por ejemplo: el facilitar las llaves, abrir el salón comunal y tener disponible el espacio para desarrollar las actividades, elementos clave para el proceso.

Por más que se busque en los libros de metodologías sobre el trabajo con comunidades en las sociedades actuales o a los teóricos más especializados de las teorías de marginalidad, difícilmente se van a encontrar sugerencias sobre cómo manejar el tema del miedo o la violencia social. Y aunque alguien tuviera alguna experiencia similar, como en la mayor parte de los temas de trabajo con comunidad, no existen recetas.

Sin embargo, antes de cambiar de tareas, se discutió con las estudiantes y se les propuso realizar dos actividades: primero, una reflexión grupal con las personas de la comunidad sobre la vivencia de los miedos; y segundo, un foro dirigido a la comunidad universitaria sobre este tema y las implicaciones para las comunidades, la Universidad y la relación Universidad-Sociedad.

¿Cómo hacemos para trabajar en comunidad un tema como el miedo? ¿Qué técnicas utilizar? No podía utilizarse un juego para abordar tal tema, pues la violencia no es para nada un juego. Tampoco se trataba de llevar una técnica que intranquilizara o provocara miedo, llevando al grupo a una crisis. En términos colectivos no es recomendable enfocarse solamente en el trauma que una situación de violencia pueda provocar porque conduce a lo que Veena Das (2003) llama comunidades de resentimiento (communities of ressentiment), es decir, una sectorización o aislamiento mayor a partir de distinciones 
binarias como víctima/victimario, buenos/malos, ricos/pobres. Esta victimización es improductiva, no permite procesar ni superar la experiencia de miedo.

¿Pero cómo abrir el diálogo ante algo tan delicado y cotidiano? Entonces se buscó potenciar un proceso creativo a partir de la realización de esculturas humanas, aportando a una reflexión sobre la corporalidad, y elaborar con el grupo lo que emergiera de esta técnica.

Una tarde se les solicitó a las señoras presentes sacar un rato para conversar de algo importante. Se narraron los hechos que habían desencadenado la reacción de miedo. (Contábamos con varias versiones de lo sucedido).

Se les preguntó si habían visto esculturas o si conocían alguna. Fueron mencionadas la de "La Chola" y "El barrendero" en el centro de San José. Se partió de ese punto para explorar las características de la escultura, ellas indicaron: "que está tiesa", "tiene una forma", "dice algo". Se les motivó a utilizar la imaginación y a crear a través de sus cuerpos las esculturas humanas.

Se les solicitó a las personas que realizaran una escultura representando el miedo. Para hacerlo se escogió primero a dos señoras de la comunidad y, posteriormente, dos de las estudiantes elaboraron su escultura. Según lo solicitara la persona que iba a crear la escultura, se dividía el grupo en tres: la persona creadora, un pequeño grupo era el material ("el barro") para hacer la escultura y otro pequeño grupo era el público que iba a verla. Esto era importante para evitar que se perdieran elementos visuales y simbólicos para la interpretación.

Antes de comenzar la técnica y al finalizar cada una de las esculturas se realizaron ejercicios de estiramiento, desplazamiento e imaginación, para mantener el cuerpo caliente y también para relajarnos y mantener la atención. Por ejemplo, se les indicaba: "ahora vamos a ser un pájaro que vuela muy muy alto y va planeando por el aire", "ahora vamos a halar un mecate para que suene una campana, muy fuerte, muy fuerte", y se les pedía que hicieran los gestos y los sonidos.

Estas fueron las esculturas que se originaron:

1) Los "modales": la primera de las representaciones elaborada por Auxiliadora fue una mesa en donde se encuentra una familia comiendo. El miedo que representa es "al sentir que no tenemos los modales para estar en la mesa, o en un restaurante y se nos quedan viendo". Lo expresado por Auxiliadora permitió conocer sobre su lugar en el mundo y los sentimientos que le acompañan. En este caso, la fuente de miedo provenía de la mirada de otros y la posibilidad de ser criticada, acompañados del temor a fallar y a no calzar en la forma de ser atribuida a una categoría social. También se desprenden aprendizajes sobre los elementos que generan inseguridades por la procedencia de la clase social a la que se pertenece.

2) La pregunta de la maestra: Georgina manifestó su temor en una situación de clase, lo cual es fundamental para el proceso dialógico en que nos encontrábamos con ellas. De nuevo se representó una mesa en la cual se encuentra una alumna; la maestra le pregunta algo y ella no sabe qué responder, "se queda en blanco". Se expresa que esa situación provoca sentimientos de vergüenza y el miedo se origina al pensar que pueda ocurrirles esa situación. Es decir, fantasear con la llegada de la pregunta y el bloqueo que provoca hablar en público. Esta representación, permitió al grupo preguntarse sobre los saberes populares. Lo representado por Georgina sintetiza el "poder del conocimiento válido o oficial", representado en "la maestra", que cuestiona al alumno o alumna. La imagen también muestra la concepción del conocimiento desde respuestas únicas y que quien sabe es quien tiene el poder para interrogar como "jerarca": ella no tendría nada que temer si la pregunta tuviera respuestas múltiples, diversas, entre las cuales está su propia elaboración. Muestra también la forma tradicional de educación bancaria (Freire, 2010), en la cual quien conoce es el o la docente y el o la alumna escucha y recibe pasivamente el conocimiento.

3) Hablar en público: Fernanda colocó al grupo como un auditorio y a una persona al frente que está exponiendo. Su ejemplo de mayor miedo era "hablar en público". Esta fue una de las representaciones que más encontró cercanía con las participantes, pues muchas expresaron "uy sí, a mí me pasa". 
En este punto se conversó sobre lo que originaba ese miedo y una de las participantes expresó una anécdota de cómo el día anterior ella había tenido que enfrentar ese miedo y animarse a hablar ante lo que consideraba era una injusticia. Lo narró como un logro, porque usualmente, ella aunque quisiera decir algo, prefería callar. Su sentimiento de liberación al superar la barrera de la vergüenza fue central para interpretar la escultura.

4) La indiferencia de la gente ante un asalto: en esta última de las esculturas se decidió que participara todo el grupo y otra variante es que se les solicitó representar "el miedo en el barrio". Andrea elaboró la imagen en la cual se encontraba una fila de personas viendo hacia un lado y en otro lugar un hombre asaltando a una mujer. La escena se da en una parada de autobús y ante la violencia que recibió la mujer, todas las personas permanecieron "viendo hacia otro lugar", es decir, su actitud fue de indiferencia. La participante indicó que esto lo había vivido en persona.

Con estas representaciones se alcanzaron reflexiones sobre nuestras vidas, nuestros sentimientos y nuestras fibras más sensibles. Las mujeres deconstruyeron el miedo, lo cual fue un principio de libertad. Dos hallazgos fundamentales surgen de estas representaciones:

1) Las mujeres viven el miedo de forma diferente a los hombres. Esto tiene que ver con cómo se ha socializado la sensación de seguridad de forma diferenciada según el género. Y en la base de estas dificultades para trabajar con las comunidades se encuentra un miedo al espacio público incorporado en la socialización de las mujeres. El temor a ser violentadas, desde el cuerpo hasta la dignidad, es constante. Tal y como lo señala Ahmed (2017):

\footnotetext{
El miedo al "mundo" como el escenario de un daño futuro funciona como una forma de violencia en el presente, que encoge los cuerpos y los coloca en un estado de temerosidad, un encogimiento que puede involucrar una negativa a salir de los espacios acotados de la casa o una negativa a habitar lo que está afuera de maneras que anticipan el daño (caminar sola, caminar de noche y así sucesivamente). Dichos sentimientos de vulnerabilidad y miedo moldean los cuerpos de las mujeres, así como la manera en que esos cuerpos ocupan el espacio. (p.117)
}

Esto se puede analizar al revisar las posiciones que asumen los discursos de la masculinidad hegemónica. El único hombre del grupo de alfabetización jugó un papel ambivalente. Por un lado, se ubicaba como el protector pero, por otro, constantemente hacía mofa del miedo que sentían las estudiantes mujeres. El punto máximo de esa burla fue cuando al llegar a una parada de autobús le hizo la "broma" a una de las estudiantes, diciéndole "deme el bolso", en referencia a que la iba a asaltar. El recurso del humor para abordar temas que causan dolor o miedo es muy común; desde la perspectiva psicoanalítica el humor permite tener un mínimo dominio sobre eso que sentimos incontrolable. Sin embargo, lesiona la posibilidad de respuesta de otras personas ante esas situaciones incómodas.

2) La impotencia acompaña al sentimiento de miedo. Como lo expresó una de las señoras: "Y es que nosotras qué podemos hacer, si somos gente de trabajo". Es difícil unir fuerzas cuando poco nos conocemos o cuando pretendemos individualizar la respuesta a la inseguridad que se siente. Por eso la pregunta sobre ¿cómo podemos apoyarnos colectivamente para enfrentar el miedo? es fundamental. Para el trabajo en comunidad esto se tradujo en el acompañamiento por parte de las personas de la comunidad a las estudiantes al llegar e irse de la comunidad. En algunas comunidades populares, las mujeres se esperan y acompañan para transitar ciertos tramos que utilizan cotidianamente por considerarlos "inseguros", recurriendo a la colectividad y a un espacio de protección colectiva. Pero en un plano más cotidiano, es clave la pregunta sobre ¿cómo revivir o establecer nuevos lazos sociales, al reconocer a vecinos y vecinas que pueden apoyarnos (dirigentes comunales, personas comprometidas)? 
Por último, en la discusión con las mujeres emergieron temas como los patrones de crianza, la violencia a lo interno de las familias, las dificultades para poner límites a los hijos e hijas, las amenazas de los hijos a sus madres, pues sus padres están siempre ausentes, y la necesidad también de recibir orientación desde la educación no formal para construir esos patrones de manejo de límites y resolución de conflictos, entre otros temas que pueden ser abordados por los proyectos de acción social.

\section{Dialogando con la comunidad universitaria}

En esta sección se abordan las reflexiones que emergieron en el marco de un foro de discusión con la comunidad universitaria. El interés de la mesa redonda y el nuestro a la vez, fue por un lado extender las reflexiones sobre el trabajo en comunidad a las aulas, y por otro, abrir la discusión para incorporar reflexiones desde distintas perspectivas que aumenten nuestra capacidad de respuesta para entender y enfrentar el miedo. Además, ésta fue una oportunidad para involucrar a profesionales y estudiantes de muy diversas áreas, con los retos que presenta el trabajo en la comunidad y la acción social universitaria. A la vez se extraen de esta discusión elementos que puede incorporar la Universidad de cara a las situaciones y retos que presenta el trabajo con comunidades. Para ello, se retoman someramente algunas de las discusiones desarrolladas por los participantes en la Mesa Redonda titulada “QQué hacemos con el miedo? Ciudades, discriminación y proyectos de Acción Social”, organizada en la Escuela de Arquitectura de la UCR, el Trabajo Comunal TC-568, el Grupo de Estudios Urbanos (GEU) y el Instituto de Investigaciones Sociales de la UCR en diciembre de 2014.

Pensando desde el barrio. En primer lugar, se contó con la participación de la señora Yerlin Montero Molina, una líder comunal activa e involucrada con el mejoramiento de la vida en su comunidad, San Juan de Pavas. Presentó un relato de vida, con su experiencia personal y un profundo análisis de las formas en que el miedo aparece y se impregna en la vida de las personas, de aquellas que viven en los barrios pobres de la cuidad, que son marginados y señalados por ello.

Montero pone sobre la mesa una discusión acerca de qué hacer cuando esa violencia se vive constantemente, cuando la violencia es la realidad cotidiana en las comunidades, y su ley es la ley del más fuerte. Ella se pregunta ¿cuáles son las expectativas de desarrollo personal para las niñas y niños que crecen en estas circunstancias? A su parecer, la condición económica es secundaria cuando se le compara con el desarrollo personal, con "proveer herramientas emocionales a los hijos para que cambien su realidad" (Montero, 2014), dificultad que señala al considerar que ella misma no las tenía como mujer de la comunidad.

Para Montero, el miedo aparece frente a lo desconocido, a lo que genera incertidumbre. Cuando se generan saberes frente al miedo, este disminuye y se aumentan las posibilidades de respuesta. Para la lideresa, al no saber cómo enfrentar los ciclos de violencia personales uno mismo se convierte en un agente de violencia, pues se reacciona violentamente. Al notar que sus hijos estaban reproduciendo estos comportamientos, Montero decide buscar herramientas que le ayuden a cambiar su situación y romper con las formas violentas de hacer las cosas.

Para Yerlin es importante informarse y conocer sobre lo que condiciona nuestra cotidianeidad. Así, por ejemplo, ella comenta el papel de un dirigente comunal, quien, al acaparar el acceso a la información (lo relativo a trámites en instituciones públicas, acceso a vivienda y gestión de proyectos en la comunidad), concentra el poder de decisión y controla a la comunidad a discreción. Esto se da, al punto que su ausencia genera una sensación colectiva de desamparo. Sin embargo, en su experiencia, cuando los vecinos y vecinas empiezan a reproducir las acciones del dirigente, se dan cuenta que pueden encontrar soluciones por sí mismos tocando las puertas correctas y organizándose para obtener una respuesta institucional.

Convertir el miedo a perder sus hogares en una herramienta para la organización es lo que ha posibilitado encontrar soluciones efectivas para su situación. Y así lo han hecho ella y su grupo, por medio de COOPEBERACA R.L., con la fundación de una cooperativa de mujeres para solventar la 
falta de empleo, rompiendo estigmas sobre los roles de la mujer en la familia, en la comunidad y en el mercado laboral, ya que se dedican al campo de la construcción.

Según la dirigente, por años el Estado se ha visto negligente ante las necesidades de las comunidades en riesgo, como San Juan. Señala que el Estado mismo fomenta el miedo y el aislamiento cuando genera una brecha en el acceso a la vivienda, en lo que se conoce como vivienda de interés social. A partir de su experiencia, la Cooperativa ha demostrado que se puede construir una vivienda de mejor calidad que las que el Estado ofrece con el bono de vivienda, pero, se les rechaza en defensa de los intereses de las inmobiliarias. De modo que, la Cooperativa se ha impuesto como misión el "informar que se pueden hacer mejores cosas y hacerlas" (Montero, 2014). Esta no es solo una forma de resolver su propio problema de acceso a vivienda, sino que, se generan fuentes de empleo de calidad a muchas familias y se insertan en una nueva dinámica social para la resolución de conflictos sin violencia. Esta reflexión es fundamental, pues permite comprender cómo el miedo se instala o reduce en un contexto social de mayor alcance, permeado por las posibilidades de habitabilidad, de bienestar y de derechos humanos que se dan en el entorno comunal y nacional.

$\mathrm{Al}$ referirse a la territorialización del miedo, Montero recupera la siguiente reflexión: "el espacio que se deja, los malos se lo apropian". Con ello trae a discusión uno de los elementos centrales en la época actual que refiere al "miedo al espacio público", mismo que Borja (2003) denomina "agorafobia urbana", y cómo la respuesta en muchos casos es alejarse de este espacio y encerrarse, pero no son lugares que quedan vacíos, sino que son apropiados por ciertos grupos para sus actividades lícitas o ilícitas, que, en ese último caso, llevarían a un deterioro socioespacial.

Como última reflexión, Montero señala la constante tensión de la dicotomía ser temido y temer. Señala que socialmente se marca a los barrios como lo otro peligroso, a lo que "hay que temer", por eso siempre hay miedo a entrar en el barrio para los que no son de ahí, a la vez que se antepone alguna razón para oponerse a que se les incluya en proyectos de conectividad urbana, pues la mejor forma de invisibilizar es el aislamiento; por otro lado, los vecinos y las vecinas del barrio siempre temen la forma en que son vistos y estigmatizados, cuando lo único diferente en ellos es la condición económica y el acceso a oportunidades para desarrollar sus capacidades.

Una visión desde las Ciencias Sociales. La participación de la Dra. Laura Chacón Echeverría (2014), psicoanalista y doctora en psicopatología, docente de la Universidad de Costa Rica e investigadora del Instituto de Investigaciones Sociales, estuvo guiada por la pregunta: ¿Qué tal si producimos el miedo mediante una nueva maquinaria? Su argumentación se centra en el reconocimiento del miedo como un constructo social, de modo que cualquier acercamiento al problema debe considerar las condiciones estructurales que lo producen y, de la misma forma, identificar nuestra posición dentro de esa estructura (por ejemplo, como estudiantes o funcionarios universitarios). A través de Gilles Deleuze (1984), Chacón se pregunta ¿cómo trabajar desde lo que una sociedad considera lo abyecto? Su respuesta es: operando un cambio del sentido, entendido este como un producto, nunca origen o fin, y que, por lo tanto, no se descubre, sino que se produce y puede producirse mediante una nueva maquinaria.

El régimen neoliberal se opone, aquí, al régimen disciplinario de Foucault (2002) en el que el interés es controlar los cuerpos de los individuos de manera que sean útiles y dóciles: "en toda sociedad, el cuerpo queda prendido en el interior de poderes muy ceñidos, que le imponen coacciones, interdicciones u obligaciones" (p. 125). Frente a estos, el régimen neoliberal busca tomar y controlar el alma, no en un sentido metafísico, sino entendida como subjetividad. Esta se expresa especialmente a través de una ideología de la positividad, en la que, por un lado, todos nos sentimos excluidos o expulsados del sistema, y por el otro, somos completamente optimistas, tanto que se nos nombra el país "más feliz del mundo" (Costa Rica). Es una tensión entre la autoexplotación, la fatiga que provoca, y el estar positivo ante eso. De manera que la vida se reduce a una pura performatividad, y a los esfuerzos por mantener esa apariencia de salud, belleza, seguridad y alegría: este es el negocio floreciente de los gimnasios, salones de belleza, empresas de seguridad y demás establecimientos dedicados a mantener la promesa de los cuerpos sanos y felices. 
Según Chacón, esta puesta en escena tiene como base un exacerbado individualismo que aísla y enfrenta a la figura del uno con el otro, distinto, desconocido y temible. "Lo otro" es lo que no es bueno, lo que no es sano, lo que no es feliz, lo que nos genera temor. Entonces, el miedo es un rompimiento del lazo social y se hace visible en la distribución socioeconómica del territorio. Desde la perspectiva psicoanalítica, la sociedad deposita los miedos en algo concreto y localizado, para poder aislarlo. Eso es, precisamente, lo abyecto, lo periférico, y un conjunto vasto de adjetivos con lo que se presenta: diferente, anormal, monstruoso, pobre, inadaptado. Por eso resulta fácil hablar de aquellos lugares donde se concentra la desigualdad y la pobreza como espacios del miedo.

Continúa Chacón, con la fragmentación de lo social se fragmenta asimismo la ciudad y el miedo es un factor clave en este proceso. Si hablamos de espacios del miedo, es posible hablar entonces de los espacios de los que temen, que suelen ubicarse en zonas de amplia concentración de riqueza, cuya principal promesa es la "seguridad". Como el espacio está cargado con estas representaciones, éstas caen también sobre quienes lo habitan y se convierte en algo común sentir miedo de acercarse a trabajar en las comunidades.

A esto se refiere con la deconstrucción del miedo desde lo abyecto. Sugiere que trabajar el miedo en comunidad significa abarcar muchas áreas que generan vulnerabilidad en las personas, desde lo emocional, el desarrollo de habilidades, la resolución de conflictos o la satisfacción de necesidades como la recreación, la gestión espacial, el acceso a vivienda o la conservación del ambiente. Para Chacón, el miedo producto del rompimiento de las relaciones humanas se hace cada vez más fuerte producto de la individualización operada desde el neoliberalismo.

El miedo es necesario porque posibilita la acción, es una necesidad para la autoconservación y el cuidado de sí; es, además, una defensa psíquica que se expresa en la fobia, pero es también una construcción social que se genera mediante una maquinaria impuesta por los regímenes de dominación: el miedo es un efecto de la desigualdad social y se refuerza desde la desigualdad social. Lo que resulta de lo anterior es la búsqueda de espacios de resistencia, que posibiliten otras formas de vivir y experimentar el barrio y la socialización. Una reconstrucción del lazo social debe darse sobre la base de una existencia en común, tomando el desafío social como grupo, dejando de lado la fragmentación que promueve el neoliberalismo.

Por su lado, el Dr. Carlos Sandoval García, profesor de la Universidad de Costa Rica e investigador del Instituto de Investigaciones Sociales, inicia su participación preguntándose: “¿qué entendemos por miedo?". Para él, el miedo se asocia con una percepción de amenaza, a veces real, a veces imaginaria. El miedo erosiona la confianza y cuando se pierde la confianza se pierde un elemento fundamental del tejido social o lazo social.

También, Sandoval indica que el miedo usualmente es difuso. A las comunidades se les asocian imágenes difusas sobre las cuales se puede decir mucho, aunque no se conozca mayor cosa. Cuando el miedo difuso se relaciona con lugares o sectores sociales específicos tiende a volverse controlable: el miedo se deposita o se proyecta en espacios, en ciertos colectivos, y eso apacigua la ansiedad que produce el miedo.

Pero, Sandoval plantea una contradicción esencial: pese a que las cifras sobre criminalidad en el país han aumentado en los últimos años, Costa Rica es uno de los países con tasas de criminalidad más bajas de América Latina. Lo que aumenta es la percepción de la inseguridad, lo cual se explica en parte por una batalla entre los medios de comunicación por quién presenta el escenario más caótico.

Sandoval propone cuatro vectores para el aumento de la sensación de criminalidad:

1. Fuerte criminalización de la pobreza. Se asocia que el peligro está en ciertos lugares, comunidades empobrecidas.

2. Criminalización de la inmigración. Se cree que sin extranjeros no habría violencia, aunque las tasas desmientan esta idea pues la inmensa mayoría de actores en disputa son costarricenses. 
3. Criminalización de las personas jóvenes. Buena parte de los eventos y arquetipos que se usan para referirse a los protagonistas de la violencia refieren a personas jóvenes, por ejemplo, "tierrosas" y "chatas"1.

4. Criminalización de la protesta social. Somos uno de los países donde las personas participan menos de las organizaciones cívicas o ciudadanas. A esto se suma que la asociatividad o realización de acciones de protesta sean vistas como un delito.

Esta definición de los agentes de la inseguridad trata de volver más controlable la sensación de miedo que sentimos, es perceptible y como sociedad no es difícil poder identificarlos. Frente a esta estigmatización que viven las comunidades, el trabajo en las mismas representa un reto y la oportunidad de hacer un contraste entre esos discursos y su experiencia. Y, sin embargo, se pregunta Sandoval ¿por qué resulta difícil reconocernos en esa diversidad y en esa desigualdad? Costa Rica es uno de los pocos países de América Latina dónde la desigualdad crece. Esto aumenta la fragmentación social y espacial y tiende poco a poco a naturalizarse como parte de nuestras relaciones sociales y de nuestro imaginario. Con ello, se recalca que el análisis de las subjetividades se debe enmarcar en el plano estructural que contiene las relaciones sociales en las que tienen lugar las mismas.

Por eso, indica en su reflexión, el trabajo en comunidad condensa mejor que gran parte de la literatura académica esta experiencia. Además, hay una retribución constante de ese trabajo, desde las iniciativas comunitarias hacia la universidad. De modo que poco a poco se va cambiando la sensibilidad de las personas participantes en el trabajo de campo, al tiempo que los barrios empiezan a tener un rostro humano, más cercano a la realidad.

\section{Conclusiones}

Todo proceso de trabajo con comunidades es aprendizaje. Es importante reconocer cómo el tema del miedo lleva a reflexionar sobre otros múltiples temas, por mencionar algunos: la violencia, las relaciones entre los géneros, la discriminación y el proceso dialógico de los aprendizajes.

Estas reflexiones sobre el miedo permitieron abrir un espacio para cuestionar las violencias, desde las que se enfrentan cotidianamente, hasta las que se viven en los hogares. Y se llegó a una importante conclusión: mucho tiempo y esfuerzos se han utilizado en trabajar el tema de los derechos, especialmente, en el caso de los niños, niñas y adolescentes en su derecho a vivir sin violencia; sin embargo, las mujeres expresan una gran contradicción: "Se nos dice que no les podemos pegar y hasta los mismos hijos nos amenazan con echarnos al PANI (Patronato Nacional de la Infancia), pero no se nos dice cómo criarlos, cómo educarlos de otra manera”. Esto abre a discusión las herramientas con las que cuentan las generaciones actuales de madres y padres para educar a sus hijos e hijas sin el castigo físico, igualmente, esto refiere a la ausencia de alternativas en la resolución de conflictos y manejo de los límites en la actualidad.

La presencia de la policía, la que casi siempre constituye el mayor contacto con la institucionalidad estatal en los barrios (Wacquant, 2006), es eventual y las personas sienten que la misma no tiene mayor incidencia sobre las problemáticas que enfrentan. Sin que se abogue por la constante requisa y extrema intervención, hemos constatado en las comunidades la indiferencia y a veces posicionamiento al margen de las autoridades respecto a lo que afecta la tranquilidad de los barrios. El sentimiento de inseguridad se magnifica cuando no existen relaciones estrechas entre los vecinos y las vecinas o cuando no se da la posibilidad de articular acciones concretas contra la violencia, lo que muchas veces lleva a una total indiferencia o miedo a involucrarse.

1 "Tierrosa" y "chata" son términos despectivos para referirse a las y los jóvenes de sectores populares respectivamente, son denominaciones acompañadas de estigmatización a estos sujetos. 
Queda para reflexión también, analizar cómo los lugares de procedencia de las y los estudiantes marcan significativamente sus posibilidades de empatía y superación de dificultades como la violencia en comunidad.

A partir de una experiencia sobre las situaciones en las comunidades se han logrado otras deliberaciones, pero cabe aclarar que esta es una primera elaboración sobre el tema. Decidimos no paralizarnos ante el miedo, sino intentar que emergieran ideas de esta experiencia difícil.

Para concluir esta reflexión se brindan algunos insumos para el Trabajo Comunal y otros proyectos que trabajen con comunidades. En la experiencia en Acción Social durante estos años hemos escuchado diversas recetas a la pregunta sobre qué hacer ante la "inseguridad" y el trabajo con comunidades. Algunas personas han expresado "lo que hay que hacer es andar una bolsa plástica transparente nada más con la sombrilla y no llevar nada", otras somos de la idea de que las condiciones óptimas de trabajo se generan con una relación constante con las personas de la comunidad que propician la protección al grupo de trabajo. Sin embargo, las labores de estudiantes de Trabajo Comunal presentan particularidades como las intervenciones de corto plazo, la intermitencia en la presencia en los lugares, la rotación de personas en un mismo proceso o la rotación en las actividades, lo que a veces hace difícil alcanzar relaciones de confianza y un proceso más amarrado en el tiempo.

No obstante, es un reto para las y los docentes o personas encargadas de facilitar estos procesos el construir esas articulaciones que sobrevivan a las características propias de la dinámica, particulares en el tiempo y el espacio. Es una reflexión inminente cuestionar por qué se enseña metodologías de la investigación o se trabaja con manuales metodológicos y técnicas desapareciendo los afectos que se producen en estas relaciones humanas que se han establecido en el campo. Con ello también se omite pensar en las subjetividades que interaccionan en estos procesos y las implicaciones que tienen tanto para unas como para otras personas. Se trata de procesos sobre los que cabe aplicar la reflexividad, en el esfuerzo por construir una comunicación "no violenta".

Como se señaló al inicio de este artículo, trabajar el miedo que se siente en estas labores no se encuentra aislado de una recuperación de la dimensión ética en el trabajo en comunidad (Paniagua, 2012). Con respecto a una posición política y ética, que acompaña la Acción Social, sostenemos que no es posible "huir" de las comunidades a pesar de las situaciones de violencia que ocurren en nuestro entorno. Se pueden identificar los miedos que generan estos trabajos, discutir cómo pueden manejarse y gestionar las condiciones en las que se generan dichos miedos, para hacerlos más llevaderos. También es valioso crear reflexiones respecto a estos temas y las medidas de protección a tomar con las personas de las comunidades, a manera de protocolos de gestión de riesgo, que pueden establecerse en la formación de las y los docentes y en el acompañamiento que den las escuelas a los trabajos de campo en todas las disciplinas, más allá de los proyectos de acción social. Pero esto no es suficiente.

Uno de los aprendizajes desarrollados en este texto consiste en que, en el trabajo con estudiantes y comunidades, así como instituciones o grupos organizados, se recomienda el establecimiento de protocolos de trabajo que permitan tener la flexibilidad para trabajar elementos de la diversidad de características sociodemográficas, pero que brinden un marco de referencia sobre lo que se recomienda hacer, lo que no y cómo proceder ante ciertos incidentes. También se hace urgente una mirada hacia dentro, insistiendo en que se requiere una revisión permanente de nuestro quehacer de forma autocrítica (Paniagua, 2013).

En el año 2017, la Escuela de Sociología, implementó el documento denominado "Criterios para trabajos de campo", un primer paso en la constitución de marcos de referencia para las y los estudiantes y docentes, sobre cómo proceder en las comunidades. Dos elementos centrales en dicho documento fueron los siguientes: 1) Es importante evitar la generación con las comunidades de falsas expectativas o compromisos que no se cumplirán, o lo que es lo mismo, la relación de confianza y vínculo se sostiene sobre acuerdos alcanzables. 2) Es de gran peso realizar la devolución a la comunidad de los productos (textos, informes, memorias, mapas, etc.) en los que las personas participaron durante el trabajo de campo. Un elemento central a desarrollar en futuras investigaciones y reflexiones sobre este tema refiere 
a las conexiones con la experiencia de género y la construcción del miedo, en torno a las condiciones, respuestas y posibilidades que da la condición genérica frente a las experiencias.

\begin{abstract}
Por último, cabe señalar un aspecto que diferentes autores y autoras han reflexionado, y que estuvo presente en la convocatoria sobre este tema, que es la restauración del lazo social, la cual solo puede venir acompañada de un esfuerzo colectivo y de búsqueda de cambios a nivel estructural. El miedo debe ser analizado en las relaciones sociales en las cuales tiene lugar, desde las subjetividades y la activa reciprocidad de los vínculos. El involucramiento con las comunidades debe cuestionar nuestras certezas y prioridades, que se articulan desde nuestra posición en la universidad, construyendo vínculos a sabiendas de que somos personas provenientes de realidades diferentes que entran en diálogo, y que deben cuestionar constantemente las condiciones para que ese intercambio se sostenga.
\end{abstract}

\title{
Referencias
}

Ahmed, Sara. (2017). La política cultural de las emociones. Ciudad de México: Centro de Investigaciones y Estudios de Género-UNAM.

Araya, María del Carmen. (2010). San José. De París en miniatura al malestar de la cuidad. San José: EUNED.

Barrera, Juan Antonio. (enero-febrero 2010). El miedo colectivo: el paso de la experiencia individual a la experiencia colectiva. El Cotidiano, (159), 5-10.

Bauman, Zygmunt. (2007). El miedo líquido. La sociedad contemporánea y sus temores. Buenos Aires: Paidós.

Borja, Jordi. (2003). La Ciudad Conquistada. Madrid: Alianza Editorial.

Caldeira, Teresa. (2007). Ciudad de muros. Barcelona: Gedisa.

Chacón, Laura. (diciembre, 2014). Foro ¿Qué hacemos en el miedo? Ciudades, discriminación y proyectos de acción social [Audio]. Escuela de Arquitectura e Instituto de Investigaciones Sociales de la Universidad de Costa Rica, San José.

Das, Veena. (2003). Trauma and testimony. Implication for political community. Anthropological Theory, 3 (3), 293-307.

Elias, Norbert. (2016). Introducción: ensayo teórico sobre las relaciones entre establecidos y marginados. En Establecidos y marginados. Una investigación sociológica sobre problemas comunitarios. (p. 27-71). Ciudad de México: Fondo de Cultura Económica.

Focás, Brenda, \& Kessler, Gabriel. (enero-febrero 2014). ¿Responsables del temor? Medios y sentimiento de inseguridad en América Latina. Nueva Sociedad, (249), 137-148.

Foucault, Michael. (2002). Vigilar y castigar. Nacimiento de la prisión. Buenos Aires: Siglo Veintiuno Editores.

Freire, Paulo. (2010). Cartas a quien pretende enseñar. México: Siglo Veintiuno Editores.

Kortanje, Maximiliano. (2009). Aristóteles, Hobbes y Castel: miedo, civilidad y conceso. Nómadas, Revista Crítica de Ciencias Sociales y Jurídicas, 23 (3), 1-8.

Montero, Yerlin. (diciembre, 2014). Foro ¿Qué hacemos en el miedo? Ciudades, discriminación y proyectos de acción social [Audio]. Escuela de Arquitectura e Instituto de Investigaciones Sociales de la Universidad de Costa Rica, San José.

Paniagua, Laura. (2012). El trabajo con comunidades: notas para el aprendizaje. Reflexiones, 91 (1), $39-52$

Paniagua, Laura. (2013). La educación liberadora: construcción de una estrategia para reflexionar las fronteras de clase. En Didáctica Universitaria: experiencias docentes en la Universidad de Costa Rica. Departamento de Docencia Universitaria, UCR, 39-58.

Sandoval, Carlos. (diciembre, 2014). Foro ¿Qué hacemos en el miedo? Ciudades, discriminación y proyectos de acción social [Audio]. Escuela de Arquitectura e Instituto de Investigaciones Sociales de la Universidad de Costa Rica, San José. 
Valdez, Andrés; Huerta, Delia, \& Pérez, Octavio. (2014). El miedo como estrategia "ganadora": El caso de la elección presidencial en México, 2006. Revista de Ciencias Sociales, 145 (3), 133-146.

Wacquant, Loïc (2006). Castigar a los parias urbanos. En Antípoda, 2, 59-66. Recuperado de: http:// redalyc.uaemex.mx/pdf/814/81400205.pdf 
